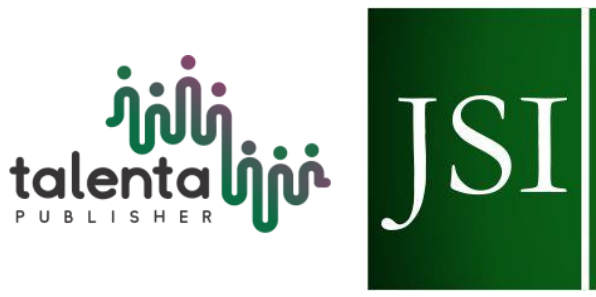

Journal of

Sylva Indonesiana

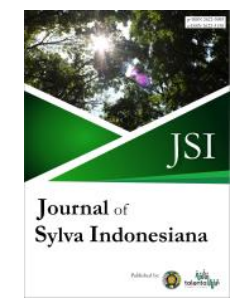

\title{
The Physical Properties and The Extractive Content of Sugar Palm Stem (Arenga pinnata)
}

\author{
Rudi Hartono ${ }^{\text {, }}$ Muhdi ${ }^{2}$, John Parulian Nainggolan ${ }^{3}$ \\ ${ }^{1,2}$ Faculty of Forestry, Universitas Sumatera Utara, Medan, Indonesia \\ ${ }^{3}$ KPH XIV. Jl. Pelita No.18 Sidikalang, Sumatera Utara, Indonesia
}

\begin{abstract}
The purpose of this study was to determine of physical and chemical properties of sugar palm stem. Physical properties include moisture content, density, and shrinkage. Furthermore, chemical properties included of extractive in hot and cold water. The age of sugar palm plant used for the study was 15 years old and collected from Sidikalang, Dairi district, North Sumatra. The test sample is determined based on the axial direction of the trunk (base, middle, end) and horizontal trunk direction (near core, middle, near bark). The results showed that the average moisture content was 120.31 to $603.48 \%$, the specific gravity was 0.12 to 0.51 , and the shrinkage was 28.06 to $77.69 \%$. The extractive content in cold water was 11.66 to $87.22 \%$, while in hot water was 10 to $90 \%$. Based on the specific gravity obtained, the near bark of the stem was included in the strength classes IV and V.
\end{abstract}

Keyword: Extractive content, Physical Properties, Sugar Palm

Received 21 January 2019| Revised 26 March 2019| Accepted 2 April 2019

\section{Introduction}

Sugar palm were widely distributed plant species in North Sumatra Province. This plant utilized as material for brown sugar and alcoholic drinks in northern Sumatra, known as tuak drinks. Sugar palm plantation area has increased every year. In 2012 the area reached 5,127.85 ha with production $\mathrm{r}$ 3,227.80 tons, and in 2015 rthe area was 5,506 ha with production was 3,720 tons. The planting area was spread in 19 districts / cities in North Sumatra Province [1].

Sugar palm (Arenga pinnata) produces industrial materials we have known for a long time. Almost all parts of this plant can be utilized, for example, roots (for traditional medicine and equipment), stems (for various kinds of equipment and buildings), young leaves (for wrapping or substituting cigarette paper called kawung). The sugar palm can be used for various purposes, for example, young palm fruit as a complementary ingredient in drinks and food called kolang-

\footnotetext{
*Corresponding author at: Universitas Sumatera Utara, Padang Bulan, Medan 20155, Indonesia E-mail address: rudihartono.usu@gmail.com
} 
kaling, the sap processed into brown sugar or vinegar, the stem starch for making various kinds of food and beverages [2].

Sugar palm is one of non-timber forest products that has not been widely known by the community. It has the potential to replace solid wood as raw material for timber industries. Since need for wood increasing, further research of sugar palm stem is needed for its development.

Unfortunately, this species has not received proper attention from stakeholders to seriously developed or cultivated, although the demand for products produced by this plant, both for export and domestic needs, continues to increase. Palm stems can be utilized as building materials and household appliances. Information about the physical and chemical properties of palm sugar is not widely known.

Based on this, initial efforts should be made to find out the physical and chemical properties of sugar palm as the right alternative for the possibility of utilization as a substitute of solid wood. In addition, preserving the species is also needs to be done.

This study aims to determine the physical properties of sugar palm stem including moisture content, density, and shrinkage volume as well as the chemical properties such as solubility of extractive substances in cold water and solubility of extractive substances in hot water.

\section{Research Method}

\subsection{Material}

The materials used in this study were palm sugar stem, filter paper, and water. The tools used were saw, ovens, calipers, desiccators, digital scales, powder makers, petri dishes, stirrers, funnels, and erlenmeyer.

\subsection{Method}

\section{A. $\quad$ Tree selection}

The materials used in this study were 3 sugar palm stems, obtained from Sidikalang, Dairi District. The samples were 15 years of age and no longer productive in producing sap.

\section{B. Sampling}

Samples were cut into $50 \mathrm{~cm}$ logs taken from different parts of stems: the base, middle, and end. The cross-section cut samples were also taken from different parts: the part edge, the center, and the core. 


\section{Testing of physical properties}

The physical properties test was conducted according to British Standard 373 in 1957, involving density, moisture content, and volume shrinkage as parameters. Samples were cut on the size of $2 \times 2 \times 2 \mathrm{~cm}^{3}$, weighted to obtain initial wet weight, and fan-dried for two weeks. Dried samples then weighted and sized to obtain dry weight and air-dried volume. Samples then oven-dried on the temperature of $103-105{ }^{\circ} \mathrm{C}$ to obtain oven-dried weight and volume. These treatments allowed the calculations of moisture content, specific gravity/density, and shrinkage.

\section{Testing the levels of extractive substances}

The chemical properties test was conducted according to TAPPI T 207 om-88 standard, which was solubility of extractive substances in cold water and solubility of extractive substances in hot water. Two grams of the powdered sample on the petri dish was put into the oven for 24 hours on the temperature of $103 \pm 2{ }^{\circ} \mathrm{C}$ to obtain oven-dried weight. After weighing, the powder's moisture content was calculated using this formula:

$$
\mathrm{MC}=\quad\{(\text { Initial weight }- \text { Oven dried weight }) /(\text { Oven dried weight })\} 100 \%
$$

Oven dried weight count (ODW count) was calculated using this formula:

$$
\text { ODWcount }=\text { Initial weight } /\{1+(\mathrm{MC} / 100)\}
$$

Oven dried weight count was needed to calculate extractive substances' solubility on cold water and hot water.

1. The solubility of extractive substances in cold water

Two grams of powdered sample was put into an erlenmeyer, then water was added until the content reached $300 \mathrm{ml}$. The sample then stored for 48 hours, stirred occasionally before strained using filter paper. The sample was washed until the filter was colorless, then was put in the oven for 6-12 hours with the temperature of $103 \pm 2{ }^{\circ} \mathrm{C}$. The sample was cooled into the desiccator, then weighed to get the Oven Dried Weight (ODW). The weight of the filter paper was also calculated.

2. The solubility of extractive substances in hot water

Two grams of powdered sample was put into a $300 \mathrm{ml}$ capacity erlenmeyer, then $100 \mathrm{ml}$ water was added before processing on a water-bath for three hours. Then the sample strained using filter paper, washed using hot water until the filter was colorless, and was put into the oven for 6 to 12 hours on the temperature of $103 \pm 2{ }^{\circ} \mathrm{C}$. The sample was cooled into the desiccator, then weighed. The weight of the filter paper was also calculated. 
The Solubility of extractive substances in cold and hot water is calculated using the following formula:

$$
\text { Solubility }=\{(\text { ODW count }- \text { ODW }) / \text { ODW }\} 100 \%
$$

\section{Results and Discussion}

\subsection{Physical Properties}

\section{A. Moisture content}

The results showed that the moisture content of sugar palm stem ranged from $120.31 \%$ to $603.48 \%$, as shown in Figure 1.

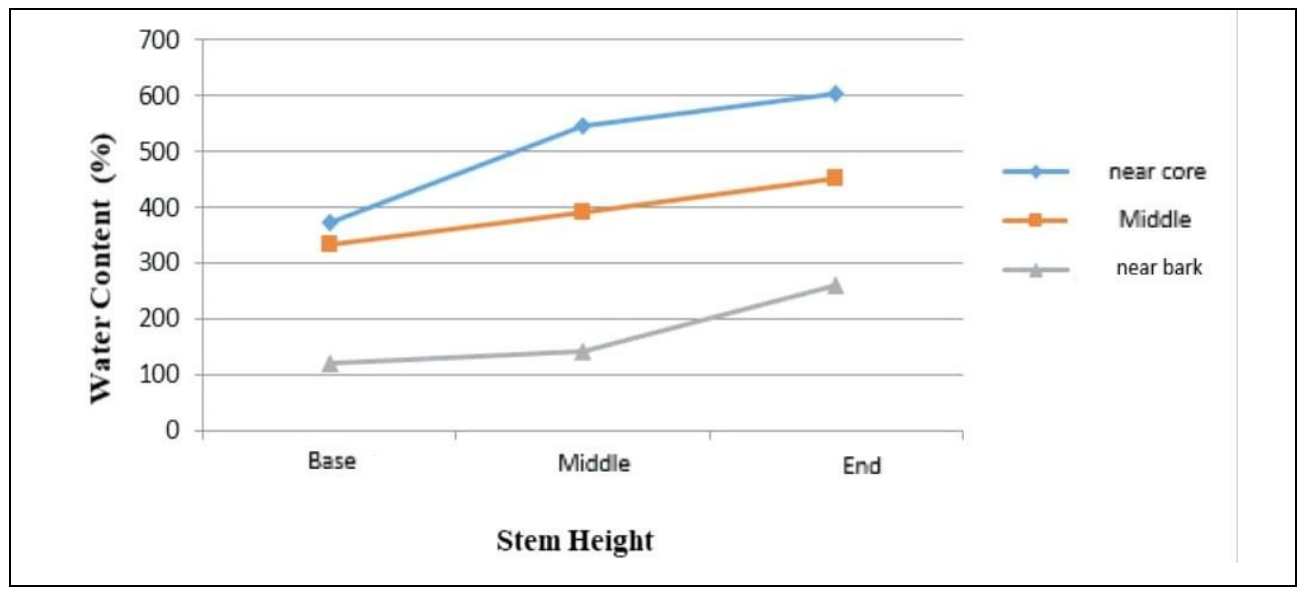

Figure 1 The moisture content of sugar palm stem based on height and depth

As seen in Figure 1, the moisture content of sugar palm tended to increase from the base to the end of the stem on the vertical perspective. Horizontally, there was a tendency that the moisture content of the sugar palm stem increase from the direction of the edge towards the core.

The value of the moisture content of the sugar palm stem was almost the same as the value of the moisture content of the palm oil stem. The value of the moisture content produced was very high, even more than $400 \%$. The inner part (near the core) had greater moisture content than the edge and middle parts of the sugar palm cross-section because the amount of parenchymal proportion was very large in the area and decreased towards the edge. According to [4] and [5], the proportion of parenchyma is high in the stem center and decreases towards the edge. Conversely, the proportion of vascular bundle was very small in the center of the stem and was higher towards the edge. The number of vascular bundles outwards was increasing (Figure 2). 


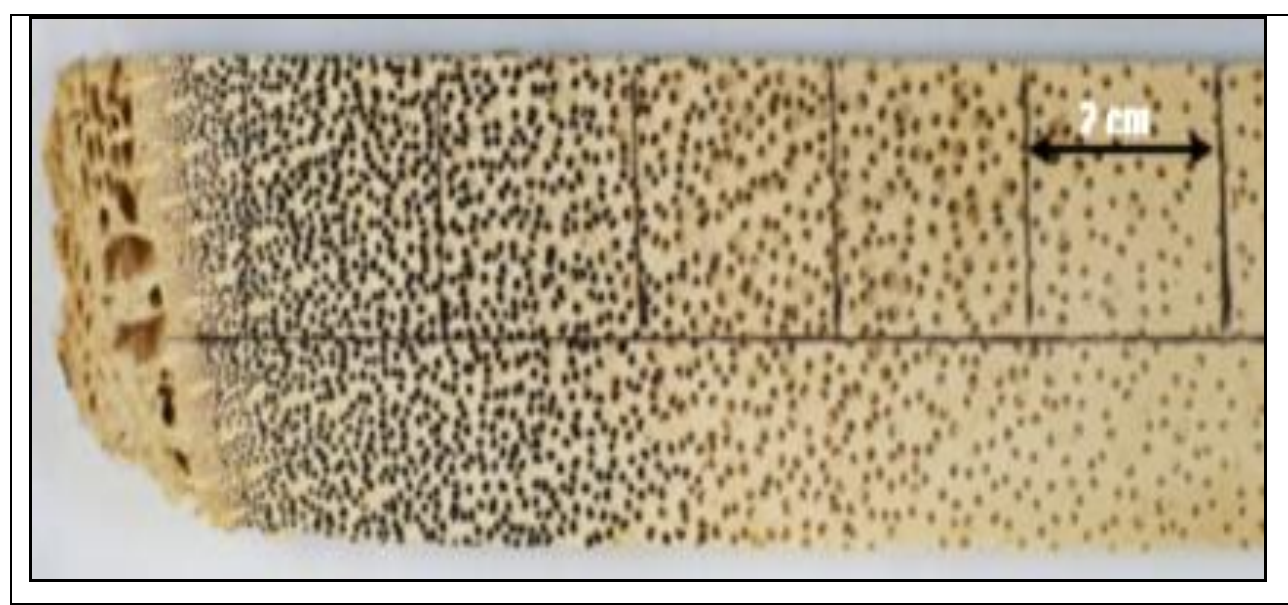

Figure 2 Distribution of vascular bundles on oil palm stem from the edge to the center.

Source: [4]

Variation of moisture content in sugar palm stem was caused by differences in the number of vascular bundles that increased from the center or core to the edge. In comparison, the moisture content of the oil palm stem [5] is much lower than the sugar palm stem. The average moisture content of oil palm wood ranged from 156.3 - 421\%, while the sugar palm ranged from 120.31 $603.48 \%$.

\section{B. Density}

The results showed that the density of the sugar palm stem ranged from 0.12 to 0.51 . The value of the density of the sugar palm stem is presented in Figure 3.

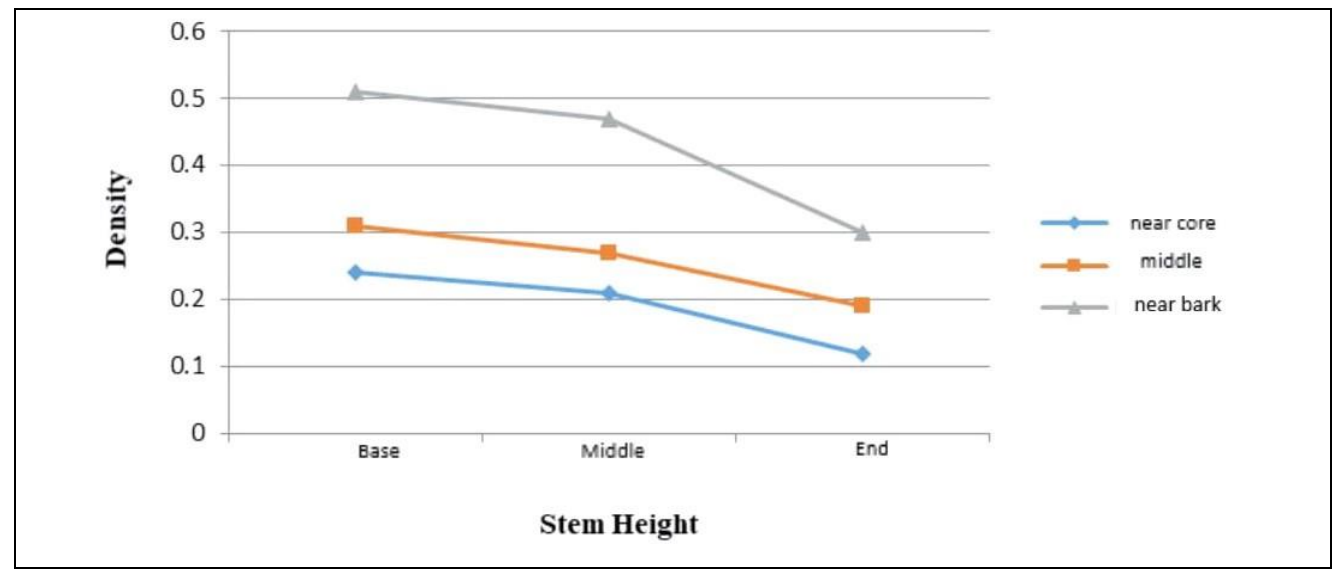

Figure 3 The density of sugar palm stem based on the height and depth

As presented in Figure 3, the value of sugar palm stem density tended to decrease from the base to the end of stem, on a vertical perspective. Horizontally, there was a tendency that the density of sugar palm stem decreased from direction of the edge towards the core. 
Based on the depth of the stem, the edge had the highest density value and decreased towards the center or near the core. As expressed by [6], the higher the position of the stem, the lower the density value.

Classified as palm species, sugar palm, oil palm [5, 7] and coconut [8] are have similar stem characteristics which are formed by vascular bundles and basic parenchyma. The proportion of the vascular bundle is high at the stem edge and decreases towards the center. Vascular bundles consist of a single chain of phloem and xylem tissues surrounded by parenchyma. The distribution of vascular bundles in this plant is not even which is relatively small in the inner or core part. Therefore, density was also low (Figure 4).

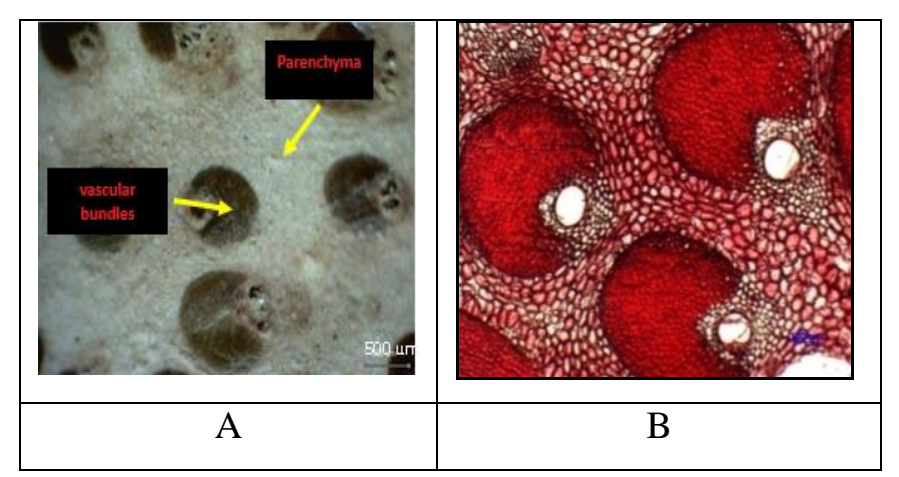

Figure 4 An overview of the macroscopic (A) and microscopic (B) structure of an oil palm stem consisting of vascular bundle and parenchyma. Source [7]

Based on the average density values, the strength class of sugar palm wood was estimated to be $\mathrm{V}$ to IV. The cross-section of the central and middle part of the stem belong to strength class $\mathrm{V}$ $(<0.3)$, while the edge belongs to strength class IV $(0.3-0.4)$.

Table 1 Wood strength based on species

\begin{tabular}{ll}
\hline Strength Class & Specific Gravity \\
\hline I & $>0.90$ \\
II & $0.60-0.90$ \\
III & $0.40-0.60$ \\
IV & $0.30-0.40$ \\
V & $<0.30$ \\
Source [9] &
\end{tabular}

\section{C. $\quad$ Volume shrinkage}

The results showed that the volume shrinkage of sugar palm stem ranged from $28.06 \%$ to 77.69\%. The volume shrinkage value is presented in Figure 5. 


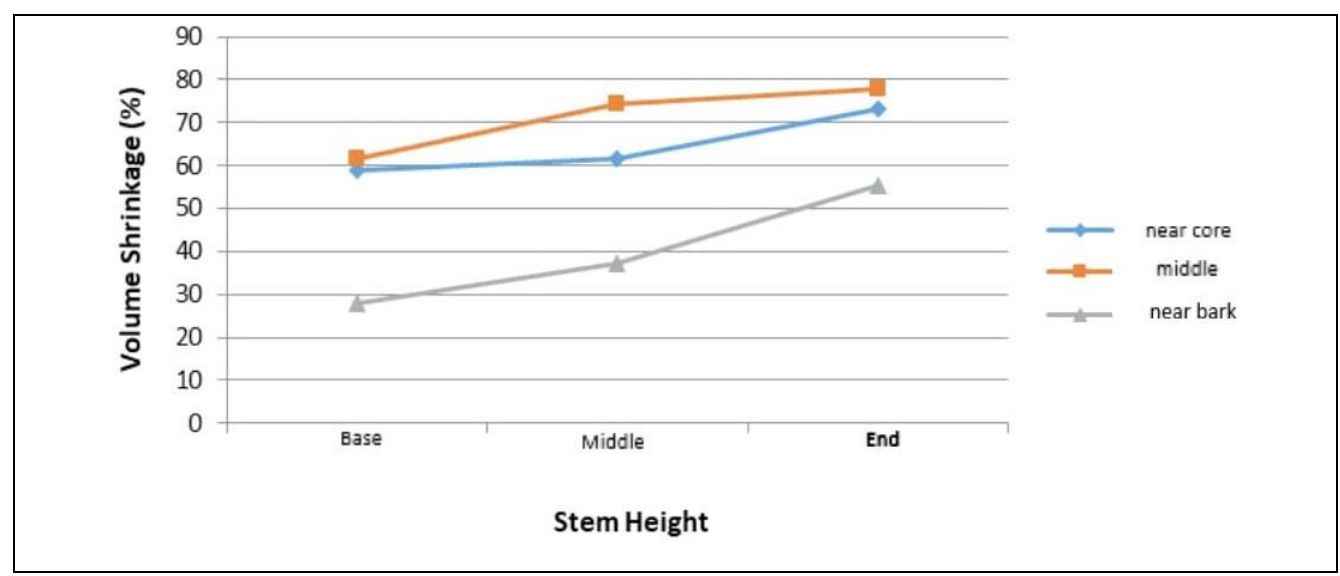

Figure 5 Volume shrinkage value of the sugar palm stem based on the height and depth

The shrinkage volume tended to vertically increase from the base towards the end. Horizontally, the center of the stem had the highest shrinkage volume value, followed by the part near the bark. The lowest value was at the edge (Figure 5).

According to [10], the number of vessel files can lessen the percentage of wood parenchyma capable to contain water, causes the part near the bark or the outer part of the sugar palm stem to shrink less than the other segments.

A serious problem in utilizing sugar palm stem is the high shrinkage value. This greatly affects the dimensional stability of the wood. The high value of shrinkage causes the dimensional stability of sugar palm wood to be low and can be a problem in its utilization.

\subsection{Extractive substances level}

The level of the extractive substance of the sugar palm stem was obtained through the immersion on cold and hot water. The result showed that cold water immersion produced an average solubility of extractive substances ranging from $11.66 \%-87.22 \%$ (Figure 6) and hot water immersion produced values ranged from $10 \%-90 \%$ (Figure 7).

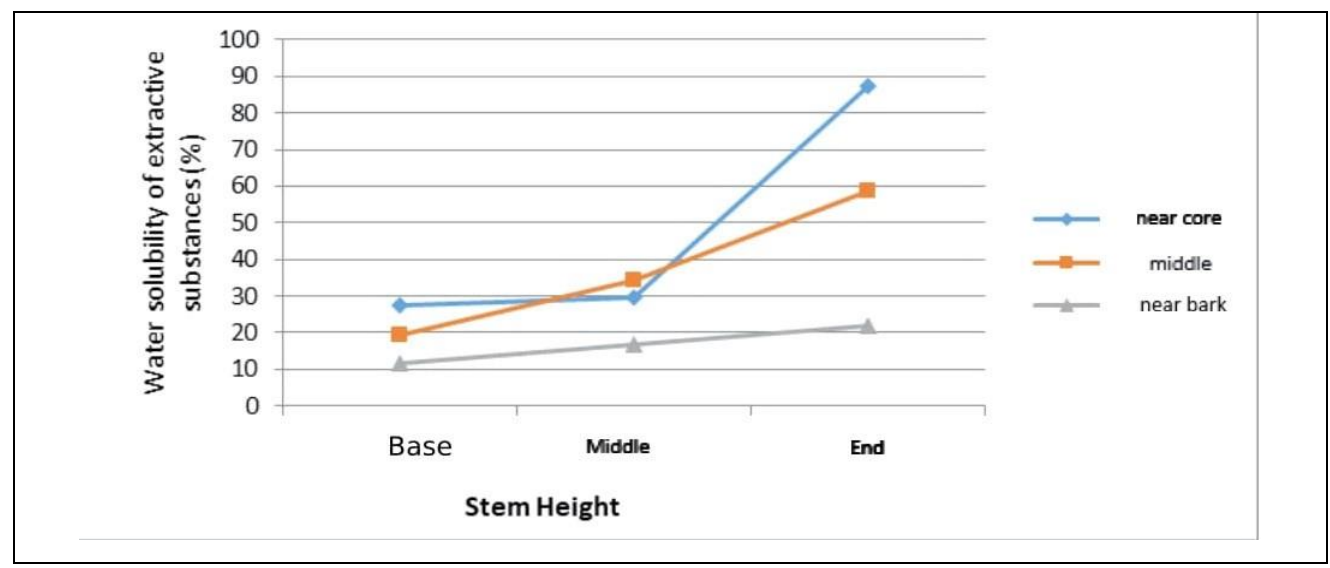

Figure 6 The value of solubility of extractive substances with cold immersion on sugar palm stem based on the height and depth 


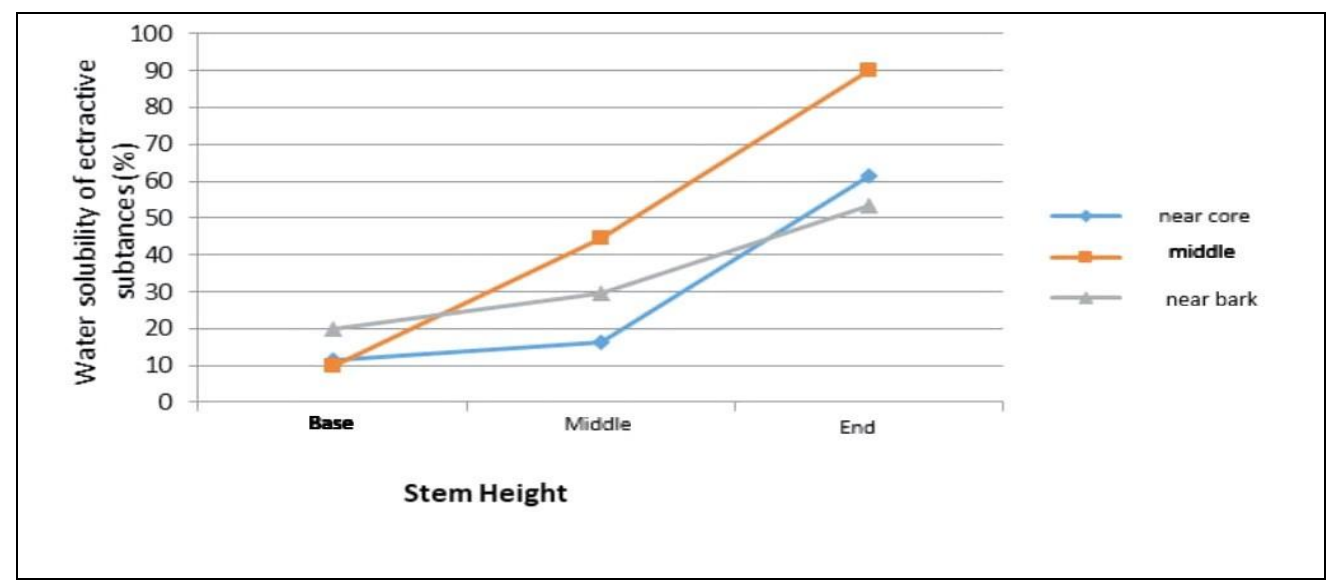

Figure 7 The value of solubility of extractive substances with hot immersion in sugar palm stem based on the height and depth

The extractive content of sugar palm tended to increase vertically from the base to the end of the stem (Figure 6 and Figure 7). Similarly, the extractive substance of the sugar palm stem tended to horizontally increase from the direction of the bark towards the core.

The solubility of extractive substances in cold water was less than the solubility of extractive substances in hot water. We suspect this was due to the solubility of extractive substances in hot water. The main components of wood such as carbohydrates, proteins, and inorganic salts are easily dissolved or dissolved in hot water in large quantities.

The value of sugar palm extracts solubility was considerable due to the high content of starch and carbohydrates in the stems. In accordance with [11], the highest extractive contents in sugar palm are starch, sugar, and other carbohydrates. This indicates that high value of solubility is caused by the main component (carbohydrate: starch) is easily dissolved in large amounts when immersed in water.

If comparing hot water solubility factor, the starch content of oil palm stem ranges from $24.54 \%$ to $60.33 \%$ [5] while sugar palm stem contains extractive substances ranging from $10 \%-90 \%$. Therefore, we can conclude that the starch content of sugar palm stems was more than that of oil palm stems.

The extractive content in sugar palm was very high. When compared with extractive substances in mangium wood according to [12], the solubility in cold water ranges from $3.00 \%$ to $4.17 \%$ and in hot water $6.02 \%$ to $9.26 \%$. This is easy to conclude because the most abundant substances in sugar palm are starch and other carbohydrates, while mangium wood contains tannins, lignin, and other compounds. According to [13] that the extractive content in wood is usually less than $10 \%$. 
The considered problem in the utilization of sugar palm stems is high content of sugar or starch. This condition causes several species of fungi and thrive both on the surface and inside of stem. It might be related to the chemical characteristics of sugar palm stems that have extractive substances (in particular, starch) and will cause difficulties in the advanced processing stage of palm wood.

Similarly, the use of sugar palm as a raw material for buildings will cause problems, in particular, the shrinking volume and high levels of extractive substances. Therefore, continuous research is needed to modify the sugar palm stems properties so that they can be utilized properly. Some researchers have used palm sugar as raw material for a wood floor or parquet [7]. Other uses are impregnating oil palm stem structure with resins such as formaldehyde phenol [14]. Impregnation will improve the quality of physical, mechanical, and durability of sugar palm stem.

\section{Conclusion}

1. The value of moisture content and shrinkage volume of sugar palm stem vertically increased from base to the edge, and horizontally increased near the bark towards the core. Conversely, the value of specific gravity decreased from the base towards the edge and from the part near the bark towards the core.

2. Levels of extractive substances of sugar palm stem both using cold and hot water were very high. The value of extractive substances with cold immersion reached 11.66 to $87.22 \%$, while the hot immersion was 10 to $90 \%$.

\section{REFERENCES}

[1] BPS Sumatera Utara, “ Province of North Sumatra in Figures 2016," Central Statistics Agency of North Sumatra Province. 2016

[2] H. Sunanto, Cultivate and Multipurpose of Sugar Palm, Kanisius, Yogyakarta, 1993.

[3] R. Hartono, I. Wahyudi, F. Febrianto, W. Dwianto, "Measurement of the Maximum Compaction Rate of Palm Oil Bars," Journal of Tropical Wood Science and Technology, vol. 9, no. 1, pp. 73-83. 2011.

[4] Erwinsyah, "Improvement of Oil Palm Wood Properties Using Bioresin," Dissertation, Institut für Forstnutzung und Forsttechnik, Fakultät für Forst-, Geound Hydrowissenschaften, Technische Universität Dresden, 2008.

[5] I.S. Rahayu, "Basic Characteristics of Vascular Bundle and Parenchyma of Oil Palm Timber (Elaeis guineensis Jacq) in Relation to Physical, Mechanical, and Durability Properties," Thesis of the Forestry Science Study Program, PostGraduate Faculty of IPB, Bogor, 2001.

[6] A. Nuryawan, A. Tarigan, L Hakim, "The feasibility of Sugar Palm (Arenga pinnata) Trunk for Raw Material of parquet (wood flooring)," in 1st Annual Applied Science and Engineering Conference. IOP Conf Series: Materials Science and Engineering 180 (2017)/012017, doi: 10.1088/1757-899X/180/1/012017. 2017.

[7] R. Hartono, I. Wahyudi, F. Febrianto, W. Dwianto, W. Hidayat, J.H. Jang, S.H. Lee, S.H. Park, N.H.Kim, "Effect of Phenol Formaldehyde Impregnation on The Physical and Mechanical Properties of Soft-Inner Part of Oil Palm Trunk". J. Korean Wood Sci. Technol, vol. 44, no. 2, pp. 172-183. 2016. 
[8] I.Y. Wardhani, "Study of Basic Nature and Compaction of Coconut Wood (Cocos nucifera L).", Dissertation of the Post-Graduate School of IPB, Bogor, 2005.

[9] I. Kartasujana, and M. Abdurahim, Indonesian Trade Timber Its Properties and Uses," Forest Products Research Institute, Bogor, 1979.

[10] A. Supriadi, R. Osly, dan S. Edy, "Characteristics of Dolok and Properties of Sawmill Palm (Elaeis guineensis Jacq)," Forest Product Research Bulletin Bogor vol. 17, no. 1, 1999.

[11] P. Haryanto and P. Philipus, The Potential and Utilization of Sago, Kanisius, Yogyakarta, 1992.

[12] M.S. Rena, D. Saptadi, and Saepuloh, "Chemical Composition of Acacia mangium Willd Wood from Several Age Levels of the Results of the First Rotation Plant," Forest Product Research Bulletin Bogor, vol. 17, no. 1, 1999.

[13] E. Sjostrom, Wood Chemistry: Basics and Use, Gadjah Mada University Press, Yogyakarta, 1995.

[14] R. Hartono, W. Hidayat, I. Wahyudi, F. Febrianto, W. Dwianto, J.H. Jang, N.H. Kim, "Effect of Phenol Formaldehyde Impregnation on The Physical and Mechanical Properties of Soft-Inner Part of Oil Palm Trunk," J. Korean Wood Sci. Technol, vol. 44, no. 6, pp. 842-851. 2016. 